\title{
NEW APPROACH ON THE ALLOCATION OF WEAR ALLOWANCES - A CASE STUDY
}

\author{
Schubert, Dominik (1); Rohrmoser, Andreas (2); Hertle, Sebastian (1); Wartzack, Sandro (3); \\ Hagenah, Hinnerk (2); Merklein, Marion (2); Drummer, Dietmar (1)
}

1: Friedrich-Alexander-Universität Erlangen-Nürnberg, Institute of Polymer Technology; 2: FriedrichAlexander-Universität Erlangen-Nürnberg, Institute of Manufacturing Technology; 3: FriedrichAlexander-Universität Erlangen-Nürnberg, Engineering Design

\begin{abstract}
To maintain functional tolerances of gear sets over their lifetime, especially in polymer-seel gear sets, the wear behaviour must be considered. The state of the art in wear modelling does not take the run-in behaviour of polymer-metal contacts into account. This results in oversizing of wear allowances in the stationary wear phase and undersizing in the run-in phase. Therefore, a modified wear model is presented in this paper. With this method the issues of over- and undersizing can be eliminated.

The method is then applied in a case study to show two things. Firstly, using the presented method the calculated necessary wear allowances were reduced by $30 \%$. Secondly, the effect of surface structures on the wear behaviour was investigated. It is shown that the run-in process is not dependent on roughness in sliding direction, but on overall contact area. Thus, the state of the art, i.e. tolerating only the roughness in sliding direction, is insufficient. Considering the process-induced surface topology during design of gear sets can decrease run-in wear. Together with the optimised wear model, this allows wider manufacturing tolerances and thus lower costs during production.
\end{abstract}

Keywords: Surface structure, Wear, Design practice, Tolerance representation and management, Optimisation

\section{Contact:}

Schubert, Dominik

Friedrich-Alexander-Universität Erlangen-Nürnberg

Institute of Polymer Technology

Germany

schubert@1kt.uni-erlangen.de

Cite this article: Schubert, D., Rohrmoser, A., Hertle, S., Wartzack, S., Hagenah, H., Merklein, M., Drummer, D.

(2019) 'New Approach on the Allocation of Wear Allowances - A Case Study', in Proceedings of the 22nd International Conference on Engineering Design (ICED19), Delft, The Netherlands, 5-8 August 2019. DOI:10.1017/dsi.2019.358 


\section{INTRODUCTION}

Due to beneficial properties, like good dry running capabilities and cost-efficient production by injection moulding polymer components are increasingly used in tribological systems (De Baets et al., 2014). However, polymers have lower wear resistance than metals. Consequently, polymer-metal contact systems experience significant wear and as a result changing geometric deviations during their lifetime, e.g. polymer gear sets in actuating drives. Since geometric deviations from the ideal form lower product quality and function (Wartzack et al., 2011), sufficient wear allowances need to be considered.

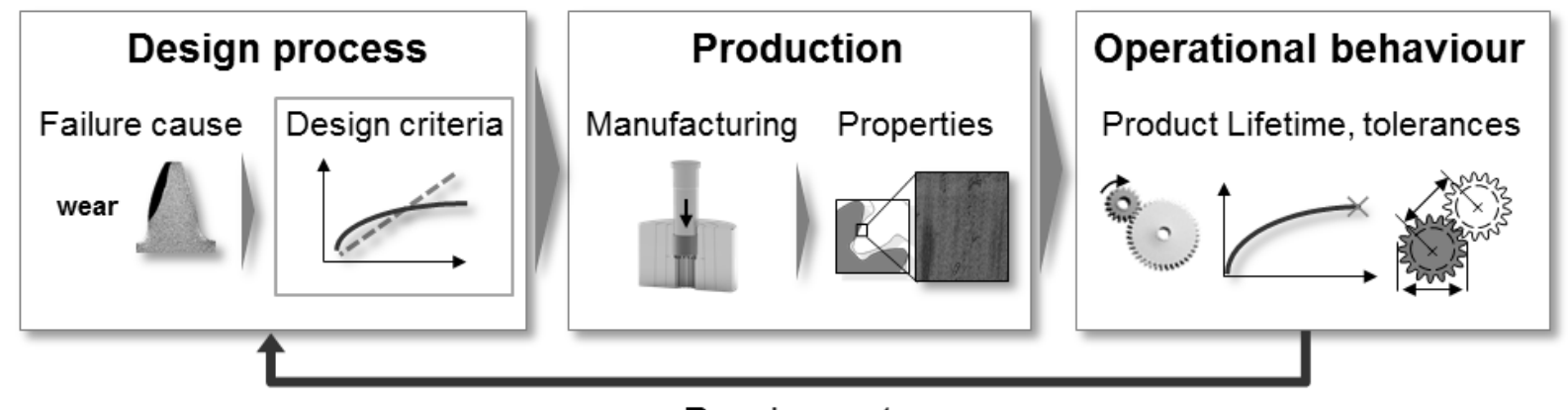

Requirements

Figure 1: Schematic process of functional tolerancing

There are frameworks, like Geometric Variations Management (Schleich et al., 2018) or ProcessOriented Tolerancing (Schleich \& Wartzack, 2013) that integrate wear allowances in the design process to ensure the requirements for product functionality are met even despite dimensional changes due to wear, see figure 1 . However, in the context of tolerance design, these allowance should neither be needlessly big, to avoid oversizing and reducing available manufacturing tolerances during production; nor should they be too small, risking reduced system lifetime. Thus, for the determination of wear allowances, as essential design criteria, the accurate assessment and description of the operational behaviour of a given system is a key factor (Zhang \& Daniel Fang, 1999; Schleich et al., 2018).

Polymer materials in tribological systems with metals as second contact body display a distinct wear behaviour. There is a run-in phase with typically higher nonstationary wear rates, followed by a phase of usually lower stationary wear rates (Czichos, 2018). The behaviour can be explained by the fact that the two contact surfaces adapt to each other. Additionally, wear debris of the polymer over time forms a separating and wear reducing interlayer between the two contact surfaces (Ye et al., 2018). This general behaviour can be seen in model systems, such as pin-on-disk tests, as well as in more complex systems, such as gear tests (Faatz, 2002). This wear process is usually described using an empirical wear coefficient model, for example the local flank wear coefficient (Feulner, 2008). However, although there is a significant run-in phase, this is often disregarded in the modelling and design of wear allowances, and in the design of polymer gears in general.

Therefore, in this article the state of the art in determining wear allowance as part of the design process is discussed and an approach for the allocation of wear allowances in tolerance design for polymer gears with regard to the run-in phase is presented. Furthermore, the main influences on the wear behaviour of polymer-metal contacts are shown. Based on this, a case study is conducted on the influence of the surface structure of the steel pinion on the run-in behaviour and the resulting wear allowances of the steel-polyamide gear sets.

\section{FUNDAMENTALS}

\subsection{Determination of wear allowances for polymer gears}

To be able to assign wear allowances within the design process, the wear of the components has to be estimated. State of the art in wear modelling is the use of a wear coefficient model to predict component wear (Feulner, 2008; DIN ISO 7148-2, 2014; VDI 2736, 2016). The wear coefficient k is an experimentally determined system parameter characterising the wear behaviour of tribological 
systems. For gears Feulner (2008) proposed the widely adopted local flank wear coefficient $k_{W}$. It is defined as the ratio of local flank wear $W_{\text {local }}$, load cycles $N_{L}$, local specific sliding in the measurement point $\zeta$, and line load, determined by local normal force and gear width as $F_{n, l o c a l} / b$. Thus, the expected wear can be calculated as defined in equation 1 :

$$
W_{\text {local }}=k_{W} \cdot \frac{F_{n, l o c a l}}{b} \cdot N_{L} \cdot \zeta
$$

The local wear is usually determined by gear wear tests, taking an initial measurement before the test and one after a determined amount of load cycles, usually 1 million cycles. However, due to run-in effects this method tends to underestimate the wear during run-in and overestimates wear during operation (VDI 2736). In addition, there is the issue, that due to the mathematical formulation of the model, there will always be a systematic error in the estimated wear, depending on the used measurement point. To solve this issue it is suggested to amend the wear model, adding a run-in wear constant $\mathrm{R}$.

$$
W_{\text {local }}=k_{W} \cdot \frac{F_{n, l o c a l}}{b} \cdot N_{L} \cdot \zeta+R
$$

Compared to the model used by VDI 2736, which was proposed by Feulner, this requires one additional wear measurement, but increases the accuracy of wear prediction significantly and decreases the necessary wear allowances see figure 2 .

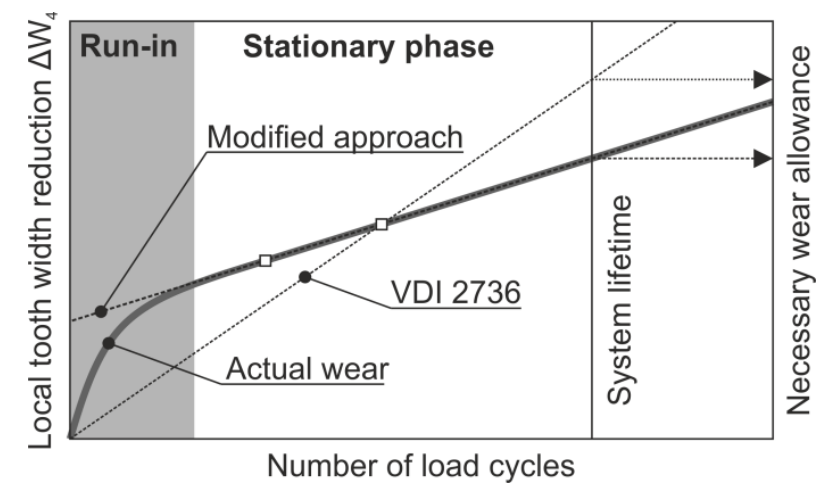

Figure 2: Comparison between the state of the art (VDI 2736) and the proposed approach

In the proposed model, there are two intrinsic factors influencing the necessary wear allowance, the wear rate $\mathrm{k}$ and the run-in constant $\mathrm{R}$. The focus of research activities is mostly on the stationary wear phase, and the wear rate $\mathrm{k}$ (Czichos \& Habig, 2010). However, the run-in wear can also determine the overall lifetime of a tribological system significantly. If there is a high amount of wear during run-in, the lifetime of the gear can be significantly reduced (Schubert et al., 2019), compared to systems with lower run-in wear, figure 3.

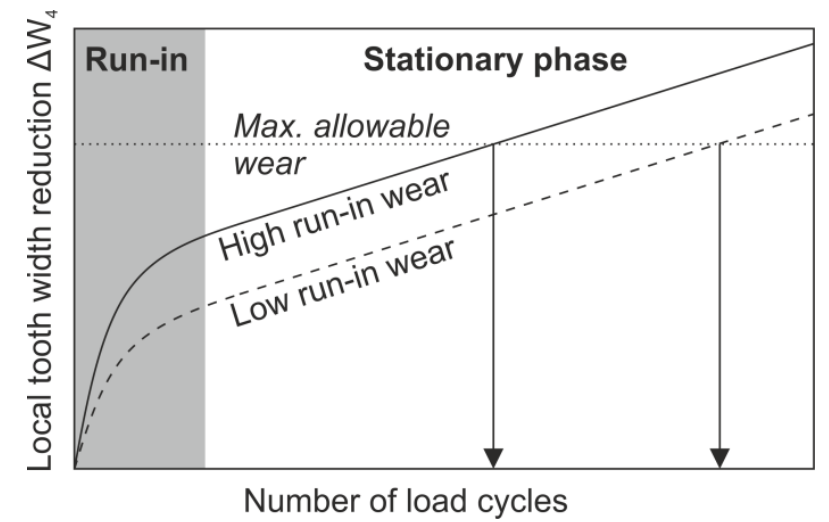

Figure 3: Relationship between run-in wear $R$ and lifetime of a gear set (schematic)

To be able to design and manufacture components in such a way as to optimise the run-in behaviour to extend the lifetime of polymer-metal tribological systems, it is of great importance to gather knowledge about influences on the run-in behaviour of these systems. 


\subsection{Influences on the wear behaviour of metal-polymer tribological systems}

Although there is a significant run-in-phase for polymer-metal-contacts, the main focus of current research is on the stationary wear processes. The research in this field focuses on four main influencing factors on the wear behaviour of polymer-metal tribological systems: material modifications of the polymer, e.g. with fibres (Friedrich et al., 1993; Sathishkumar et al., 2014), lubricants (Yao et al., 2003), or nanoparticles (Sorrentino, 2018); process induced microstructure of the polymer (Künkel \& Ehrenstein, 2003; Fischer et al., 2014); load conditions (Faatz, 2002; Feulner, 2008); and geometry of the contact partners (Briscoe, 1981). Much research has been done on the influence of the contact geometry on wear behaviour on a microscopic scale, based largely on Briscoe's work (1981). One of the main influences on the behaviour of tribological systems and the run-in behaviour is the roughness stucture of the two interacting surfaces (Ye et al., 2018). On a microscopic level, wear processes can be categorized into two main wear categories: adhesive and abrasive wear processes. In reality, both processes take place simultaneously. The surface roughness of the metal part determines, which process is more pronounced (see figure 4). The smoother the metal surface, the higher the adhesive wear component, due to the increased real contact surface and higher resulting adhesive forces between the contact partners. An increase in roughness of the metal surface leads to an increased abrasive wear component through micropitting and -plowing. (Briscoe, 1981)

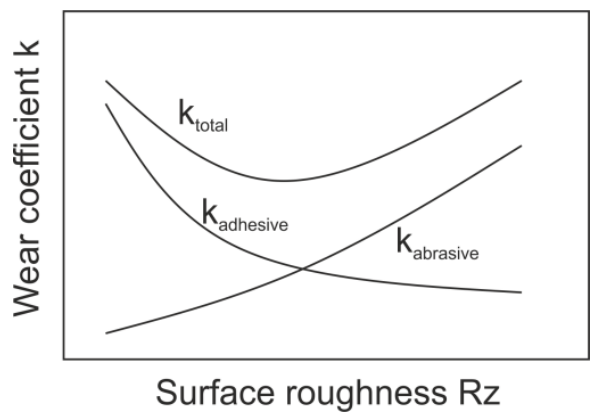

Figure 4: Optimum wear as a result of surface roughness (schematic) (Briscoe, 1981)

As research has shown, the contrary dependencies of the wear processes on the surface roughness of the metal part lead to an optimum roughness for each metal-polymer combination, depending, among other factors, on the materials, temperature and load collective. (Briscoe, 1981)

Wear is usually characterised using pin-on-disk tests, evaluating the stationary wear rates (DIN ISO 7148-2). Current research usually gives roughness parameters as a measure for the contact surface, since it is assumed that only roughness peaks and valleys parallel to the movement of the components are of importance (Ye et al., 2018). If the surface has an isotropic structure, this might be a reasonable simplification. If there is a certain anisotropic surface structure, e.g. due to processing by milling or cold forging, there might be a difference between specimens that present the same roughness parallel to the movement, but different ones in perpendicular direction. This is due to the fact that the surface area of those specimens will be significantly different. However, little to no research has been done on the effect of surface topology on wear, especially in the run-in phase.

\subsection{Process design for defined surface structures in metal and polymer gears}

With regard to a resource-saving and economic production, forming and primary forming processes offer great potential for gear manufacturing. As a basic forming procedure with comparatively simple process setup, the full forward extrusion is suitable to manufacture spur gears with average tolerance specification (Bausch, 2011). During the forming process, the surface of the gear flanks is smoothed and solidified (Kawasaki, 2007). Previous investigations have shown, that a targeted modification of the lubrication system is suitable to alter the resulting component surface in laboratory tests (Lorenz et al., 2018). These findings are applied to the metal extrusion of steel gears in order to adapt the flank surface structure and positively influence the run-in behaviour of a steel-polyamide gear pairing. For injection moulded polymer parts, the surface structure depends on the manufacturing process of the mould cavity. Due to the complex geometry, gear moulds are often wire eroded and exhibit a nonoriented surface structure. As a result of operating wear, the surface structure of the polymer adapts to the countersurface structure in the contact area after a few load cycles and is therefore not of significant influence. 


\section{MATERIALS AND METHODS}

\subsection{Materials and specimens}

This research was done on a combination of steel pinions and polymer gears. The gear size was chosen according to VDI 2736, module $1 \mathrm{~mm}$, to represent a typical gear size in actuating drives (see table 1).

Table 1:Technical specifications of the gears

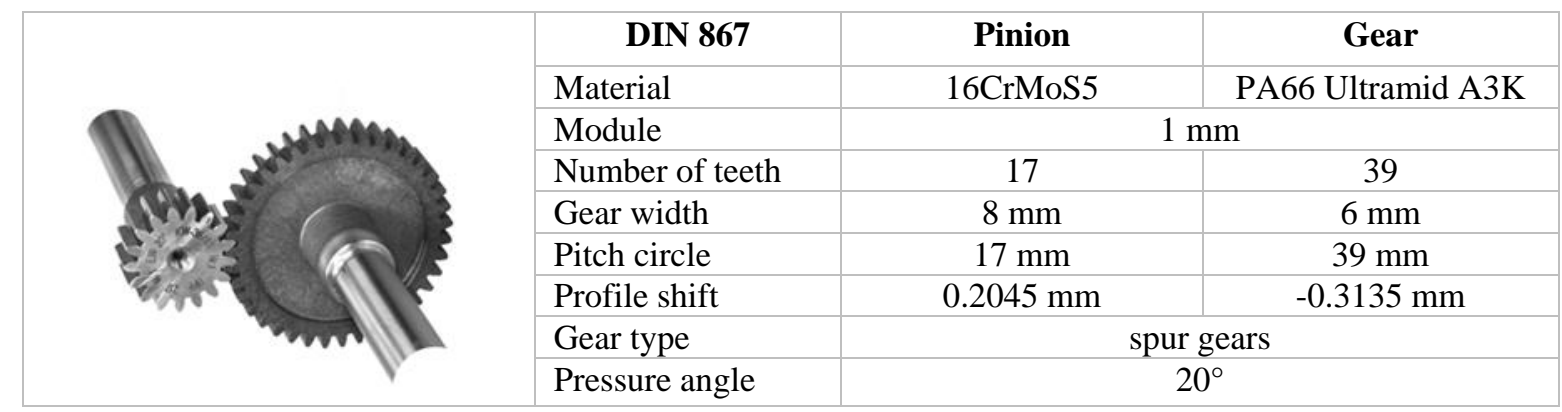

In order to investigate the influence of different, process-induced surface topologies on the run-in wear behaviour in a gear pairing, two sets of gears were extruded. One with a high friction and one with a low friction lubricant. The flanks of the extruded gears exhibit a smoothed surface with a clearly grooved structure along the forming direction. The gears extruded with a high friction lubricant (Lube MD 230 by Zwez Chemie GmbH, Lindlar, Germany, friction factor 0.068) have a smoother surface, whereas a low friction lubricant (Lube PD 470 by Zwez Chemie GmbH, Lindlar, Germany, friction factor 0.035) leads to a rougher flank surface. The friction factors of the lubricants have been evaluated in prior laboratory tests (Lorenz et al., 2018). The eroded gears optically present a nondirectional surface structure. One set of polymer gears was tested to ensure that differences in wear behaviour result only from the different steel pinions. The chosen material, Ultramid A3K, is a polyamide 66 by BASF SE, Ludwigshafen, Germany. Due to its high wear resistance PA66 is often used in gear applications. The polymer gears were produced by injection moulding using an Arburg 370U-700-30-30 by Arburg GmbH \& Co. KG, Loßburg, Germany. The main processing parameters can be seen in table 2 .

Table 2: Processing parameters for the PA66 gears

\begin{tabular}{|c|c|c|}
\hline Processing parameters & Unit & Parameter setting \\
\hline Screw diameter & $\mathrm{mm}$ & 18 \\
\hline Mass / Mould temperature & ${ }^{\circ} \mathrm{C}$ & $290 / 60$ \\
\hline Injection / Packing / Cooling / Cycle time & $\mathrm{S}$ & $1.5 / 6 / 20 / 35$ \\
\hline Packing pressure & $\mathrm{bar}$ & 700 \\
\hline
\end{tabular}

\subsection{Analytical methods}

\subsubsection{Gear measurements}

To characterise the gear and pinion geometry the diametric dimension over pins and tooth span over 4 teeth were measured at three equidistant measuring locations over the gear circumference according to DIN 21773. These measurements were recorded after each test-run to determine the run-in wear.

\subsubsection{Microscopy}

To characterise the morphology of the polymer gears $10 \mu \mathrm{m}$ thin cuts were taken from the middle of the gear across the same tooth for one exemplary polymer specimen of each group after 1 million load cycles. The images were taken on a transmitted light microscope of the type Zeiss Axiophot, by Carl Zeiss AG, Oberkochen, Germany, with polarised light to show the crystalline structure.

\subsubsection{Surface structure}

The surface structure of pinions and gears was characterised on one representative specimen before the tests and after 1 million load cycles. A scanning electron microscope (SEM) of the type Zeiss Ultra Plus by Carl Zeiss AG, Oberkochen, Germany, was used to identify changes in topology and potential material transfer. Due to the limited measuring space, the roughness of the specimens was determined, 
not confirming to the exact standard, but in good accordance to $\mathrm{Rz}$ on a 2.1 by $0.7 \mathrm{~mm}^{2}$ (axial $\mathrm{x}$ radial) sector in the test area on the flank. The measurements were carried out on a confocal microscope of the type $\mu$ Surf by Nanofocus AG, Oberhausen, Germany, with a magnification of 20. Sampling lengths of $0,42 \mathrm{~mm}$ (axial) and $0,14 \mathrm{~mm}$ (radial), a profile filter $\lambda \mathrm{s}$ of $2.5 \mu \mathrm{m}$ and a cut-off $\lambda \mathrm{c}$ of $0.8 \mu \mathrm{m}$ were used. The optical measurement was repeated for three gears of all settings and for five teeth in each case. Table 3 shows the surface parameters in radial and axial evaluation direction of the gear flank. The $\mathrm{Rz}$ values for the gears are shown in table 3.

Table 3: Overview of surface characteristics

\begin{tabular}{|l|l|l|l|}
\hline Specimen & $\mathbf{R z}$, axial $[\boldsymbol{\mu m}]$ & $\mathbf{R z}$, radial $[\boldsymbol{\mu m}]$ & $\mathbf{R z}$, geom. mean $[\boldsymbol{\mu m}]$ \\
\hline Extruded, high friction & 2.40 & 0.84 & 1.42 \\
\hline Extruded, low friction & 3.12 & 1.55 & 2.20 \\
\hline Eroded & 2.20 & 2.14 & 2.17 \\
\hline
\end{tabular}

The Rz values for gears extruded with the high friction lubrication system are lower than those for the gears extruded with lower friction. This is due to increased smoothing of the surface during forming. The surface parameters of the eroded gears show no difference between axial and radial direction. The $\mathrm{Rz}$ values in radial, i.e. stress direction of the extruded gear with high friction and the eroded gear are similar, whereas the geometric mean of the eroded and the extruded gear with low friction are equal. When comparing the different surface parameters in axial and radial directions, the significantly lower roughness of the extruded gears into the axial direction (forming direction) can be seen. This is also detectable in the SEM images on the steel gear surfaces (figure 6).
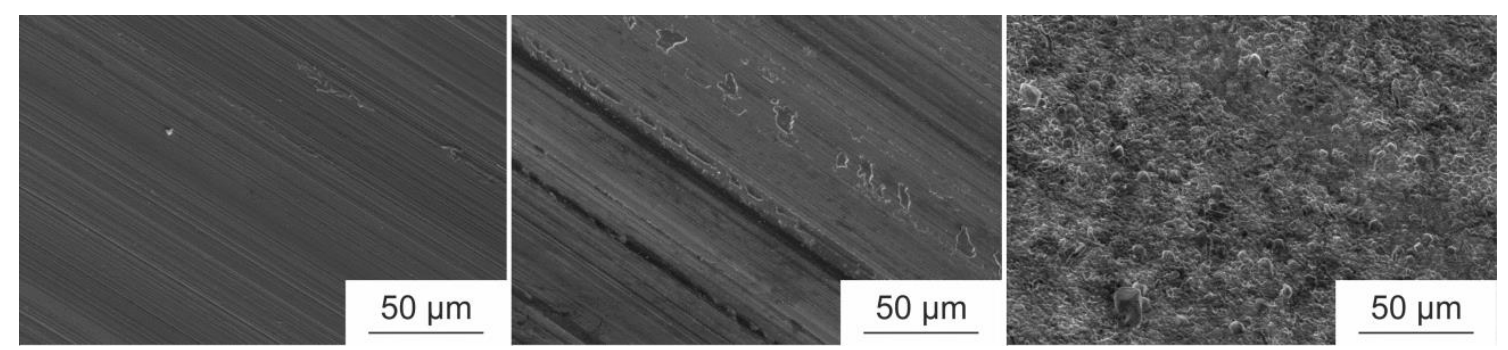

Figure 5: Initial surface topology of the investigated steel gears - metal extruded $R z 2.40 \mu \mathrm{m}$ (left), metal extruded $R z 3.20 \mu \mathrm{m}$ (middle) and wire eroded $R z$ 2.14. $\mu \mathrm{m}$ (right)

\subsubsection{Run-in wear}

To compare the wear models in a case study, run-in tests were performed on the LKT test rig (see figure 7). Each set of pinions was tested with three specimens in four test runs. One test run was defined as 4.1 hours at $1.0 \mathrm{Nm}$ output torque and 1,000 rpm output speed, resulting in approx. 250,000 load cycles per test run, 1 million load cycles in total. One specimen of each category was tested 1.25 million cycles to ensure that the phase of stationary wear had been reached. After initial measurement, the gears were taken out of the test rig after each test run and geometrically measured to determine the wear.

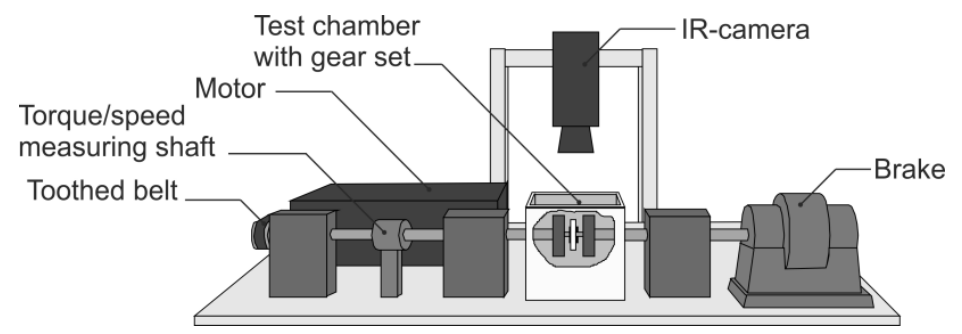

Figure 6: Schematic of the LKT test rig, according to (Feulner, 2008)

The calculations are performed on the measurements at 1 million cycles for both wear models, and using the values at 750,000 cycles as the second measurement for the new approach. The boundry conditions are assumed for the measuring diameter $d_{M}=38 \mathrm{~mm}$ as follows: local specific sliding $\zeta=0.69$, calculated according to Schlecht (2010), and line load, $\frac{F_{n, \text { local }}}{b}=\frac{2 \cdot M}{d_{M} \cdot b}=0.00877 \mathrm{Nm} / \mathrm{mm}^{2}$. 


\section{RESULTS AND DISCUSSION}

\subsection{Comparison of the presented wear models}

A significant difference in run-in wear can be observed (see figure 8). The metal extruded gears with $\mathrm{Rz} 2.40 \mu \mathrm{m}$ exhibit a higher tooth span reduction than the other two pairings. The metal extruded pinions with Rz $3.2 \mu \mathrm{m}$ and the wire eroded gears, however, show almost identical run-in behaviour. All pairings have reached the stationary wear phase between 750,000 and 1,000,000 load cycles.

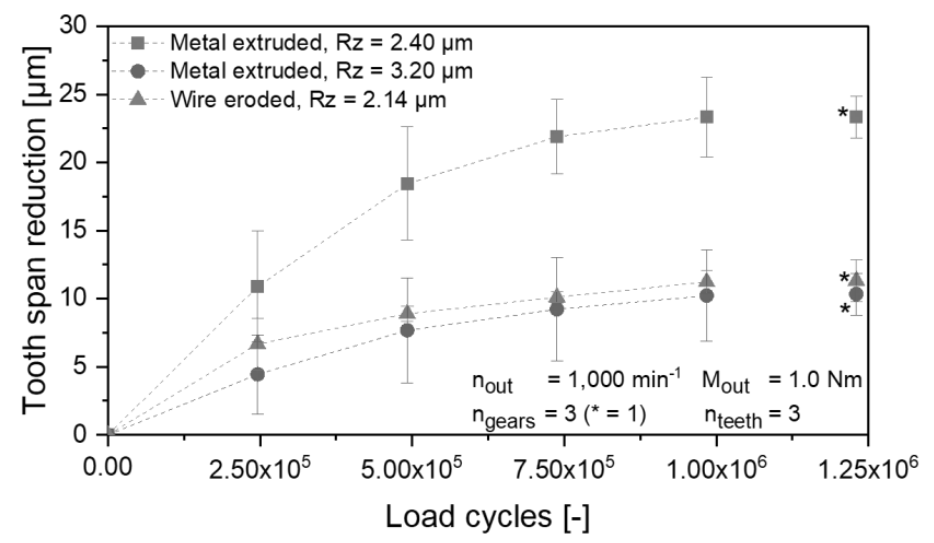

Figure 7: Run-in wear behaviour depending on pinion surface structure

A comparison of the wear models can be seen in table 4. Using the calculation for the wear coefficient as defined by Feulner and VDI 2736, the metal extruded specimen with Rz $2.40 \mu \mathrm{m}$ show a wear coefficient more than twice as high as the other specimens. This is clearly not the case, see figure 7. The suggested approach, however, shows lower and more similar wear coefficients for all specimens. Additionally, the run-in constant R gives a good estimate of the amount of run-in wear.

Table 4: Parameters of the different wear models for the presented case study

\begin{tabular}{|l|l|l|l|}
\hline Specimen & \multicolumn{1}{|c|}{$k_{\text {Feulner }}\left[10^{-6} \mathrm{~mm}^{3} / \mathrm{Nm}\right]$} & $k_{\text {mod. }}\left[10^{-6} \mathrm{~mm}^{3} / \mathrm{Nm}\right]$ & $R_{\text {mod. }}[\mu \mathrm{m}]$ \\
\hline Metal extruded, $\mathrm{Rz}=2.40 \mu \mathrm{m}$ & 3.85 & 0.95 & 17.6 \\
\hline Metal extruded, $\mathrm{Rz}=3.20 \mu \mathrm{m}$ & 1.69 & 0.66 & 6.2 \\
\hline Wire-eroded, $\mathrm{Rz}=2.14 \mu \mathrm{m}$ & 1.85 & 0.73 & 6.8 \\
\hline
\end{tabular}

The presented wear models can also be used to calculate the necessary wear allowance of a gear with an (arbitrarily chosen) predicted lifetime of 2 million cycles. The results can be seen in table 5 . It can be easily seen, that the wear allowances of the modified approach are significantly lower than the ones calculated using the wear coefficient according to Feulner. Furthermore, the wear allowances calculated with the new approach seem more plausible, given the data, represented in figure 7.

Table 5: Wear allowances calculated according to Feulner and the modified approach

\begin{tabular}{|l|l|l|}
\hline Specimen & Wear allowance (Feulner) & Wear allowance (mod. approach) \\
\hline Metal extruded, $\mathrm{Rz}=2.40 \mu \mathrm{m}$ & $47 \mu \mathrm{m}$ & $29 \mu \mathrm{m}$ \\
\hline Metal extruded, $\mathrm{Rz}=3.20 \mu \mathrm{m}$ & $20 \mu \mathrm{m}$ & $14 \mu \mathrm{m}$ \\
\hline Wire-eroded, $\mathrm{Rz}=2.14 \mu \mathrm{m}$ & $22 \mu \mathrm{m}$ & $16 \mu \mathrm{m}$ \\
\hline
\end{tabular}

Thus, it can be concluded, that the presented approach of wear modelling improves upon the state of the art by considering run-in wear. The predicted wear rates for the stationary phase are more consistent with the presented data; furthermore undersizing in the run-in phase is mathematically impossible. Lastly, the resulting wear allowances are smaller than those calculated according to existing models, preventing oversizing and allowing for wider manufacturing tolerances.

However, in the context of the function oriented design process of polymer gears, solely the description model for their wear behaviour is insufficient for an optimisation of the components to minimize wear. It is also important to understand the underlying processes that result in the 
described behaviour. Therefore, in the following the possible source of the differences in wear behaviour shall be discussed briefly and advice on the design of tolerances for surface structures shall be given.

\subsection{Analysis of the wear behaviour}

The difference in behaviour seen in the wear data and described by the wear models can be explained, if the surface structure is taken into account. The metal extruded pinion with $\mathrm{Rz} 2.40 \mu \mathrm{m}$ shows a very smooth surface before the tests, whereas the metal extruded pinion with $\mathrm{Rz} 3.20 \mu \mathrm{m}$ and the wire eroded pinion with $\mathrm{Rz} 2.14$ present considerably rougher surfaces (see table 3 and figure 6). If the geometric mean of the Rz-values in axial and radial direction is taken as a measure for surface roughness this becomes evident. The smooth metal extruded gears show a value of $1.42 \mu \mathrm{m}$, the rougher metal extruded and the wire eroded gears are almost equal with $2.20 \mu \mathrm{m}$ and $2.17 \mu \mathrm{m}$, respectively. It is reasonable to assume that due to an increased real contact surface the gear set with the metal extruded pinion with the smoother surface experiences higher adhesive wear compared to the pairings with the rougher flanks, which result in significantly lower real contact surface and therefore lower significant wear. The wear debris also supports this assumption.
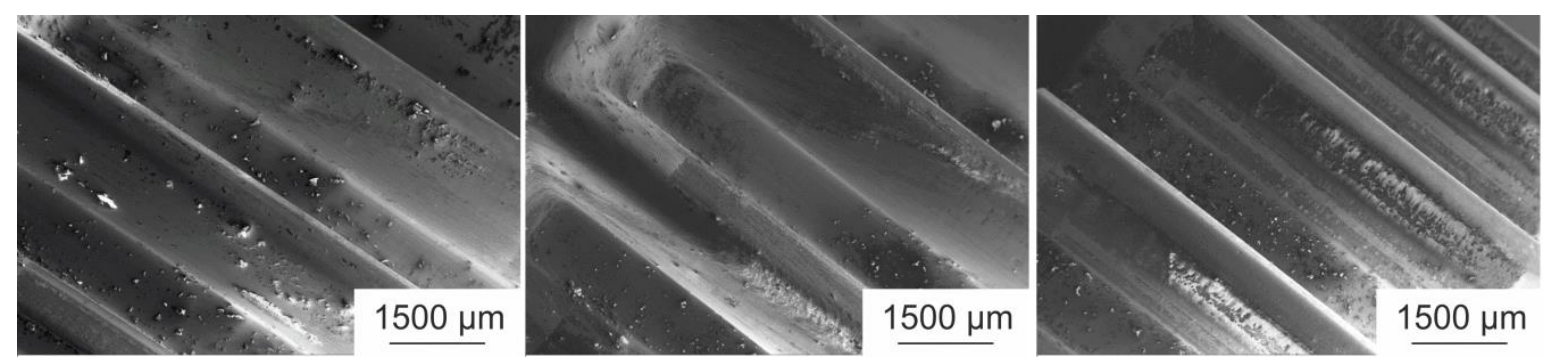

Figure 8: Polymer transfer from gear onto steel pinion after 1 million cycles - metal extruded $R z 2.40 \mu \mathrm{m}$ (left), metal extruded $R z 3.20 \mu \mathrm{m}$ (middle) and wire eroded $R z$ 2.14. $\mu \mathrm{m}$ (right)

The debris on the smoother extruded pinions is much more prominent (figure 8) and present even after cleaning the specimen in acetone for 10 minutes in an ultrasonic bath (figure 9), which indicates higher adhesive forces and therefore higher adhesive wear.
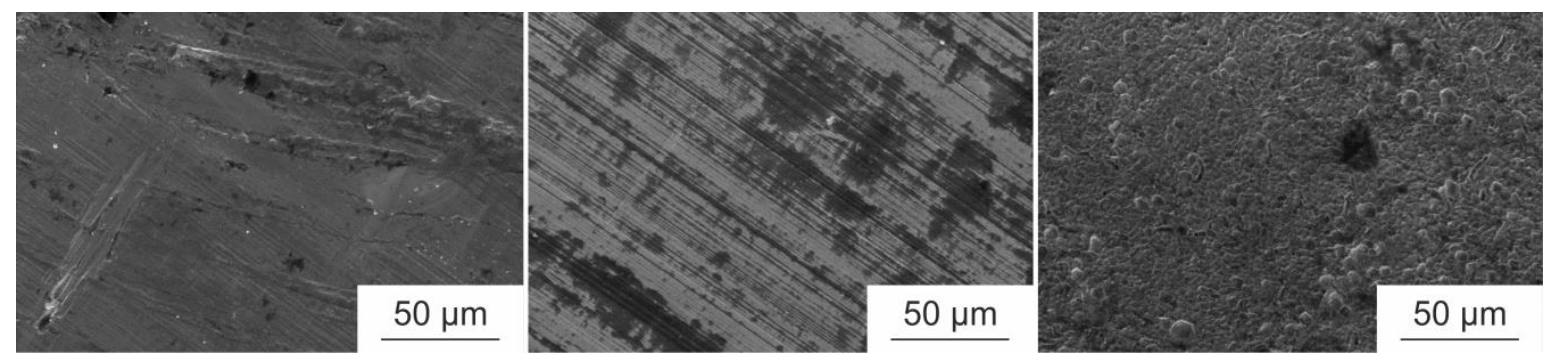

Figure 9: Surfaces of the steel pinions after 1 million load cycles - metal extruded Rz 2.40 $\mu \mathrm{m}$ (left), metal extruded $R z 3.20 \mu \mathrm{m}$ (middle) and wire eroded $R z$ 2.14. $\mu \mathrm{m}$ (right)

Thus, it can be concluded that the higher real contact surface of the smoother metal extruded gears is the reason for the differences in wear behaviour. Surface roughness parameters in sliding direction alone, however, are not sufficient to accurately describe the real contact surface and are therefore unsuitable for the prediction of the wear behaviour of a given system. The real contact surface and topology has to be considered in the design process, and a surface tolerance should be assigned, that considers the topology of the surface structure. If these aspects are taken into account during tolerancing, the necessary wear allowances can be decreased and the manufacturing tolerances can be increased significantly. 


\section{CONCLUSION}

This paper presented a modified approach for the modelling of the wear behaviour of injectionmoulded gears, especially considering run-in wear. The presented approach significantly improves the state of the art in wear modelling as described in Feulner (2008) or the VDI 2736 and provides an essential design criteria for the design process/to support tolerance design. By considering a run-inconstant, the presented approach avoids undersizing the wear allowance of polymer gears during the run-in phase and it avoids oversizing them in the stationary phase. With the modified approach necessary wear allowances in the case study are reduced from $47 \mu \mathrm{m}$ to $29 \mu \mathrm{m}$ for the metal extruded pinions with Rz 2.40; from $20 \mu \mathrm{m}$ to $14 \mu \mathrm{m}$ for metal extruded pinions with Rz 3.20; and from $22 \mu \mathrm{m}$ to $16 \mu \mathrm{m}$ for the wire eroded specimens, in each case a reduction by at least $30 \%$. All in all, the wear predictions made using the modified approach are in better accordance with the empirical data, thus, more sensible wear allowances can be allocated. This leads to wider manufacturing tolerances, which can be fulfilled more easily and less costly. The model can be used to determine, whether a certain factor affects run-in or stationary wear behaviour, simply by analysing whether the wear rate $\mathrm{k}$ or the run-in constant $\mathrm{R}$ is affected. As a proof of concept in the case study the influence of the surface structure was analysed, with the result that the run-in constant was significantly influenced by changes in surface structure, whereas the wear rate only changed slightly. However, there is need for further investigation into this new concept for describing wear. It is yet unclear how main factors like material modifications, load collective or process-induced morphological structures influence the wear behaviour in this new model. Another issue engineers face with allocating wear allowances is the missing correlation between model wear tests, like Pin-on-Disk tests, and gear tests. There is no simple factor to convert the Pin-on-Disk coefficient into the gear coefficient according to Feulner. However, since both, the modified approach and Pin-on-Disk test, determine the wear coefficient based on the stationary wear process and offer the possibility to determine run-in effects, it might be possible to find a correlation factor in future work.

Furthermore, in the presented case study the influence of surface structures on the wear behaviour was investigated. Pinions with similar Rz values in radial, i.e. sliding direction (extruded with $\mathrm{Rz} 2.40 \mu \mathrm{m}$ and eroded with $\mathrm{Rz} 2.14 \mu \mathrm{m}$ ) show very different run-in behaviour. If the geometric mean of the surfaces is considered, parts with similar mean Rz values (extruded with Rz $3.20 \mu \mathrm{m}$, mean $2.20 \mu \mathrm{m}$, and eroded $\mathrm{Rz} 2.14 \mu \mathrm{m}$, mean $2.16 \mu \mathrm{m}$ ) show similar behaviour. This indicates, that run-in processes are not dependent on roughness in sliding direction, but rather on overall real contact area. Therefore, only tolerancing roughness parameters in sliding direction is insufficient to ensure similar run-in behaviour.

The real contact area of the interacting surfaces is of upmost interest. Higher real contact areas (i.e. lower mean $\mathrm{Rz}$ ) lead to increases in adhesive wear compared to structures with lower real contact areas (higher mean Rz). To specify and tolerance the optimum surface structure, much research has yet to be done. Besides the investigation of the influence of different surface topologies (grooves, plateaus, valleys) on the run-in and stationary wear, different materials and morphologies need to be considered. Further investigations will deal also with the influence of the surface structure under varying load conditions. However, it was already shown in this paper, that considering the production process and the resulting surface topology of the parts during the design of a gear set, can decrease the run-in wear of polymer-steel gear sets significantly. As a result, lower wear allowances are required and wider manufacturing tolerances can be assigned. Thus, cost and effort during production can be reduced.

\section{REFERENCES}

Bausch, T. (2011), Innovative Zahnradfertigung: Verfahren, Maschinen und Werkzeuge zur kostengünstigen Herstellung von Stirnrädern mit hoher Qualität, expert Verlag, Renningen.

Briscoe, B. (1981), "Wear of polymers: an essay on fundamental aspects", Tribology international, Vol. 14 No. 4, pp. 231-243.

Czichos, H. (2018), “Tribological Systems”, Measurement, Testing and Sensor Technology, Springer, Cham, pp. $185-196$.

Czichos, H. and Habig, K.-H. (2010), Tribologie-Handbuch: Tribometrie, Tribomaterialien, Tribotechnik, Springer, Berlin. 
De Baets, P., Glavatskih, S., Ost, W. and Sukumaran, J. (2014), "Polymers in tribology: Challenges and opportunities", International Conference on Polymer Tribology, Bled, 11.-12.09.2014, University of Ljubljana, pp. 1-8.

DIN ISO 7148-2 (2014), Plain bearings - Testing of the tribological behaviour of bearing materials - Part 2: Testing of polymer-based plain bearing materials, Beuth Verlag, Berlin.

Faatz, P. (2002), Tribologische Eigenschaften von Kunststoffen im Modell und Bauteilversuch, Ph.D. Thesis, University Erlangen-Nuremberg.

Feulner, R. (2008), Verschleiß trocken laufender Kunststoffgetriebe - Kennwertermittlung und Auslegung, Ph.D. Thesis, University Erlangen-Nuremberg.

Fischer, C. et al. (2014), "The Influence of Proccessing Temperature on Morphological and Tribological Properties of Injection-Moulded Microparts", Advances in Mechanical Engineering, Vol. 2014, pp. 1-9.

Friedrich, K., Lu, Z. and Häger, A. (1993), "Overview on polymer composites for friction and wear application", Theoretical and Applied Fracture Mechanics, Vol. 1, pp. 1-11.

Kawasaki, Y. (2007), "High Precision (DIN 8 class) Forged Helical Gear - Manual Transaxle for Passenger Car", ICFG workshop Quality and Properties of Cold Forged Products and JSTP Forging Committee, Nagoya University.

Künkel, R. and Ehrenstein, G. (2003), "Effects of morphology on the tribological behavior of thermoplastics in sliding contact", Proceedings of the 61 st Annual Technical Conference, Nashville, Tenn, USA, pp. 1706-1710.

Lorenz, R., Hagenah, H. and Merklein, M. (2018), "Experimental evaluation of cold forging lubricants using double cup extrusion tests", Materials Science Forum, Vol. 918, pp. 65-70.

Sathishkumar, T.P., Satheeshkumar, S. and Naveen, J. (2014), "Glass fiber-reinforced polymer composites-a review", Journal of Reinforced Plastics and Composites, Vol. 13, pp. 1258-1275.

Schlecht, B. (2010), Maschinenelemente 2, Pearson Studium, München.

Schleich, B., Wärmefjord, K., Söderberg, R. and Wartzack, S. (2018), “Geometrical Variations Management 4.0: towards next Generation Geometry Assurance”, Procedia CIRP, Vol. 75, pp. 3-10.

Schleich, B. and Wartzack, S. (2013), "Process-oriented tolerancing - A discrete geometry framework", International conference on engineering design, 19.-22.08.2013, Seoul, pp. 61-70.

Schubert, D. et al. (2019), "Einfluss der fertigungsbedingten Gestalt und Struktur auf das Einlaufverhalten von Stahl-Kunststoff-Getriebepaarungen”, In: S. Wartzack, (Ed.), Industriekolloquium der Forschungsgruppe FOR 2271, Ernst Vögel, Stamsried, pp. 74-84.

Sorrentino, A. (2018), "Tribology of Self-Lubricating Polymer Nanocomposites”, Self-Lubricating Composites, Springer, Berlin, pp. 105-131.

VDI 2736 (2016), Thermoplastische Zahnräder, Beuth Verlag, Berlin.

Wartzack, S. et al. (2011), "Lebenszyklusorientierte Toleranzsimulation zur funktionalen und ästhetischen Produktabsicherung", Konstruktion, Vol. 6, pp. 63-74.

Yao, J. et al. (2003), “The influences of lubricant and material on polymer/CoCr sliding friction”, Wear, Vol. 255 No. 1-6, pp. 780-784.

Ye, J. et al. (2018), "The Competing Effects of Counterface Peaks and Valleys on the Wear and Transfer of Ultra-Low Wear Alumina-PTFE”, Tribology Letters, Vol. 66 No. 12, pp. 1-14.

Zhang, Y. and Daniel Fang, X. (1999), "Target allocation for maximizing wear allowance of running fits based on process capability”, Quality Engineering, Vol. 2, pp. 169-176.

\section{ACKNOWLEDGMENTS}

The authors would like to thank the German Research Foundation (DFG) for supporting the research project "FOR 2271 process-oriented tolerance management based on virtual computer-aided engineering tools" under grant numbers DR 421/21-1, ME 2043/55-1 and WA 2913/19-1, as well as the company BASF SE for providing research material. 